\title{
Offshore Sourcing and Reshoring: The Impact of Governance on Cost and Incentives
}

\author{
Taghreed K. A. Hikmet, Auckland University of Technology, New Zealand \\ Peter Enderwick, Auckland University of Technology, New Zealand
}

\section{Introduction}

Offshore sourcing continues to grow in importance for firms in a range of industries, and for many smaller firms it is a key step in the internationalisation process. Offshore sourcing helps firms maintain their competitiveness and meet their customers' expectations of lower prices and better quality while facing high levels of international competition. A particularly favoured location for offshore sourcing is China, which offers a number of advantages including a large and rapidly growing market, low cost resources (particularly labour and land), access to an increasingly sophisticated supply base and R\&D capability, as well as proximity to other high growth economies in Asia. In this short paper we outline the findings of a recent pilot study that examined the experience of a small sample of New Zealand-based medium- and high-technology firms engaged in offshore sourcing to China. The study is of considerable interest as it sheds light on aspects of offshoring not widely understood, in particular differences between anticipated and landed cost savings, the role of institutional weaknesses in the host country (China), and the trade-offs that result from alternative governance arrangements for offshored activities. We briefly consider the implications of our findings for incentives to re-shore activities.

\section{Cases}

To investigate the intricacies of offshoring, a qualitative research approach was adopted. Participant selection was based on three criteria: that they were key personnel with decision-making responsibility; that they had been part of the offshore decision-making process; and that the company had been involved in offshoring to China for at least two years. The sample was selected from small-medium manufacturing firms within the New Zealand high-tech industry, drawing on a relevant government database. The pilot study involved three firms, termed A, B, and C. Primary data were collected through in-depth, face-to-face interviews, and were supplemented by secondary sources including company websites, reports, and publicly accessible media. Respondents were asked a series of open-ended questions covering company background and context, the offshore decision-making process, perceived benefits, challenges experienced in China, and ways in which such challenges were addressed.

At the time of data collection, all three participants were based in Auckland, New Zealand; one of the three owned his company, while the other two participants were in partnerships. At the time of the interview, the experience of offshore sourcing ranged from 8 to 15 years. All the participants were male. One of the three was born in New Zealand while the other two participants were born overseas and migrated to New Zealand. All participants held relevant tertiary qualifications (business or technical).

\section{Key Findings}

There was a strong consistency of findings across all three case companies. Four key themes emerged from the interviews relating to the benefits and challenges of offshoring, in particular: cost savings, quality issues, challenges around intellectual property, and governance concerns.

\section{Cost Savings}

For all three respondents, offshoring to China was underpinned by costseeking motives. All respondents recognised the huge potential labour cost savings that might be achieved but also experienced additional savings in areas such as land, raw materials, and logistics. These resulted from access to specialist suppliers in China, proximity to buyers and suppliers operating in China, and reduced lead times. Overall, all three managed to reduce their landed costs, back in New Zealand, by $40-80 \%$ depending on the choice of governance mode and the degree of integration within China.

\section{Quality Improvement}

A surprising finding of the research was that all three respondents believed that offshoring to China can lead to quality improvements. While most started from the position that through offshoring they hoped to reduce costs whilst at least maintaining quality levels, they actually experienced quality improvements. The primary source of quality improvement occurred through product improvements resulting from the existence in China of a wide range of specialist suppliers and producers. Compared with the respondents' home base of New Zealand, Chinese suppliers benefitted from both larger scale and higher levels of specialisation. However, such improvements were not costless, and respondents discussed the investments that had to be made to minimise the likelihood of "quality fade" where initial quality levels, perhaps as contractually specified, were not maintained over time. Respondents believed that in many cases Chinese suppliers offered extremely low prices to attain contracts, and then sought ways to improve margins at a later stage, perhaps by lowering quality. We discuss these types of trade-off, in this case between cost savings and quality maintenance, below. Respondents mentioned the benefits of effective documentation processes and accurate translation of specifications and expectations as helpful in maintaining quality levels. 


\section{Intellectual Property Concerns}

The three respondent companies were all involved in technologically sophisticated manufacturing and had strong advantages in product design, development, or know-how, which they considered valuable firm-specific intellectual property (IP). They were aware of the risk to intellectual property in a country such as China, which is perceived as having weak IP protection laws and sophisticated suppliers capable of copying such technology. For two respondents this issue was addressed by retaining key IP within New Zealand and fitting this (typically software) when the product was brought back to New Zealand. Technical services, including R\&D, were viewed as being cost competitive in New Zealand and supported by strong IP laws. Interestingly, uncertainty over IP created an opportunity for Company $C$ to establish its own facilities in China and, in turn, to contract out to other New Zealand businesses. Company $C$ was able to offer significant assurances to other companies that they would be, in effect, operating within their home culture and context, but at Chinese cost levels. As we will discuss below, this is a further area of trade-off in the offshoring decision process.

\section{Governance Issues}

One of the most interesting findings from the pilot companies was the complexity of governance of offshore sourcing. While conceptually governance alternatives appear straightforward, the reality in emerging markets such as China is quite different. In theory, offshored operations can be managed through a wholly or majority owned facility (captive offshoring), through an arms-length or trading relation, or through some form of contractual relationship. Each offers various benefits and costs. A captive facility gives greater control over quality and IP for example, but may not offer the cost savings that domestic suppliers can achieve. A purely trading relationship may work for the exchange of standardised commodities, but it offers little opportunity for customisation or mutual learning. Contracts, while appealing in theory, are only effective if the contracting party has confidence in the host country institutional structures, particularly the legal and policy environments. Since many emerging economies are characterised by institutional weaknesses or "voids", confidence in independent enforcement may be low and may need to be supplemented by other forms of trust building or assurance.

\section{Challenges and Trade-Offs}

The major findings from this pilot study highlight the considerable complexities of offshore sourcing and the range of trade-offs or compromises that are involved. We highlight some of the major challenges that respondents discussed.

\section{Unanticipated Benefits}

The first issue is a positive one in that all respondents experienced unanticipated benefits resulting from offshore sourcing. As mentioned earlier, cost savings were the primary driver behind the offshoring decision in all three cases, coupled with an expectation that quality levels could, at least, be maintained. In practice, our respondents experienced a number of benefits other than simply cost reductions. These related to the highly efficient supply base that China offers, particularly because of the presence of experienced specialist providers. It is perhaps worth noting that buyers based in developed home economies larger than New Zealand might not experience the same secondary benefits. A presence in China was also valuable in enabling the respondent firms to be closer to their customers, many of whom had also moved operations to China, and to expand into other high growth Asian markets.

\section{Anticipated vs. Landed Cost}

A second key finding was the extent to which there was variation between anticipated and achieved cost savings. For the respondent firms, the critical determinant of cost savings was the chosen governance mode. For example, Firm C found that moving from contract manufacturing by a local specialist to operating its own wholly-owned factory in China reduced landed cost savings from 60 to $40 \%$ of total costs. The difference, some \% of costs, was due to an increase in the firm's overhead expenses as it established a factory, recruited and trained staff. Because our respondent firms also experienced an evolution in governance structures (see below) it was difficult to accurately forecast likely cost savings. Anticipated savings based solely on a comparison of wage and productivity rates is likely to be misleading since it fails to take account of governance costs.

\section{Institutional Weaknesses and Relationships}

Governance is a key issue in China because of what respondents saw as institutional weaknesses. Particular concerns were expressed about Chinese officials and administration. Difficulties of transparency, consistency, and accountability made it very difficult to accurately forecast costs and timeframes. Not surprisingly respondents recognised the value of networks and of building strong relationships if one is to do business in China. For example, Company A used its chief engineer, who was from China, to facilitate the search process in finding suitable suppliers. On the other hand, when the company moved to establish its own production facility in China, this took four years, in part because their Chinese manager did not have good relationships with local officials. Both Companies B and C also relied on their networks to reduce search costs in identifying suitable suppliers and partners. This finding should not be surprising and simply reinforces the continuing importance of China's relationship-based business system.

\section{Dynamics of Governance}

The changing forms of governance used to manage offshore sourcing by the respondent firms was a key finding, and one that is central to the future development of this research project. All three firms shifted governance structures in their offshore production in China and these stages are illustrated in Figure 1.

All three firms evolved, over a relatively short period of time, through different governance forms in their offshore production activities in China. Interestingly, the first and second stages were the same for all three.

The first stage was based on a commercial relationship sourcing from different suppliers in China. This was followed by the selection of a supplier that best matched the firm's requirements. Finding these suppliers was done in different ways such as via networks, visiting exhibitions, or through the internet. For example, Firm A made use of the company's chief engineer's network in China, where he was originally from. Firm B made use of its network in Hong Kong to find suppliers in China. Firm C found its first suppliers through visiting different electronic exhibitions in Hong Kong, China, and Malaysia. 
Figure 1: The Evolution of Governance Structures

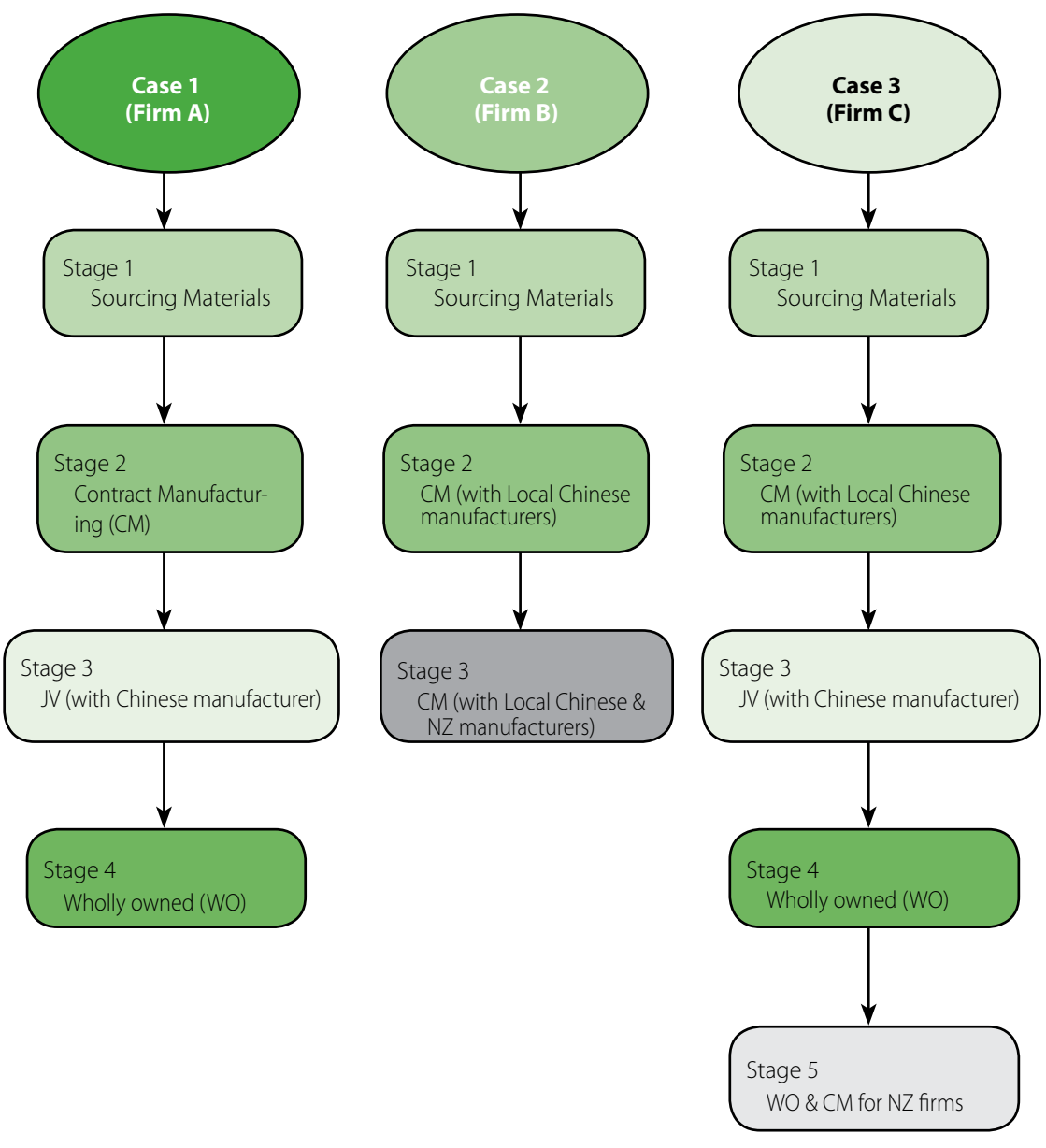

companies. Both firms reported a decrease in cost savings: Firm A's savings went from $75 \%$ to $60 \%$ while Firm C's went down from 60\% to 40\%, although they had achieved much greater control over production quality, their future goals, and their ability to target particular markets.

Firm C continued to evolve its wholly owned facility to become as a contract manufacturer for foreign businesses in the electronics industry. These foreign businesses decided to offshore their production activities to China for cost savings reasons but they were concerned about product quality and IP protection, while at the same time lacking the required financial resources to establish their own production facilities in China. Respondent $C$ reported that these customer firms managed to save $50-80 \%$ of their costs by contracting to Firm C. Firm C successfully reduced a customer's cost for producing a particular electronic controller by $80 \%$, going down from NZ\$150 to $\$ 30$, for the first batch, and eventually reaching just NZ\$13 for the balance of production while at the same time maintaining the integrity of both the customer's IP and quality of the supplied products.

\section{Impact of Offshoring on Company Competitiveness}

The final topic explored with the respondent companies was the impact of offshoring to China on the firm's competitiveness. All three firms agreed that offshoring has made them stronger international competitors. The primary impact was through cost savings. Directly, cost savings could be passed on in the form of lower prices to customers. Indirectly, the savings allowed respondents to make additional investments in new technology and machinery raising efficiency and productivity and reducing wastage. The indirect, and

The second stage for all three firms involved contracting local Chinese manufacturers to produce parts or final products. Both Firm A and Firm $B$ reported an increase in the quantity of their products on the shelf without any increase in costs. For example, Firm B reported that stocks of finished goods increased from 200 to 3000 without any cost increase. Firm C reported landed cost savings of $60 \%$. Although these levels of saving were dramatic, at this stage respondents had significant concerns about the quality of their goods as they had less control over production processes and the quality of components used in their products.

At the third stage both Firm A and Firm C formed joint ventures with one of their suppliers to increase control over production. Firm A reported the total cost saving at that stage were about $75 \%$ of landed costs. Firm B continued to use contract manufacturing but started to contract not only local Chinese manufacturers in China but also foreign manufacturers-New Zealand, American, and Australian — that had established manufacturing facilities in China.

By the fourth stage, both Firm $A$ and $C$ had exited from their joint venture (JV) relationships to establish their own manufacturing facilities in China with full control over their production, testing, and marketing. Different reasons were behind these decisions, for example Firm C's JV partner started making decisions without consulting Firm $C$ and made trade-offs between costs and quality. The reason behind Firm A's exit from its JV was due to differing goals. Firm A wished to target the local Chinese market while the other party wanted to only sell to foreign often unanticipated, effects of offshoring also contributed to competitiveness. Respondents had access to more efficient suppliers, were often closer to buyers and used their experience to move into new markets. The impact on competitiveness appeared to be both positive and strong.

\section{Implications for Reshoring}

Although other papers in this issue consider in some detail the growth of reshoring activities, our findings have interesting implications for this discussion. While reshoring appears to be prompted by changes in the operating conditions of offshore locations, to correct previous suboptimal locational choices, or to overcome operating challenges including quality, complex supply chains and a lack of flexibility, our discussion highlights other factors that managers need to consider.

The first is that the trade-off between rising costs in the offshore location and the possibility of utilising advanced production technologies in the reshored location must take into account the characteristics of the home country. For our case companies reshoring to New Zealand, a small, geographically remote economy with a limited industrial supply base, may be a less attractive option when compared to bringing processes home to economies such as the United States, Germany or Japan. In the case of an economy like New Zealand, the balance is likely to favour offshoring for the foreseeable future. Second, the nature of products offshored, often involving standardised components and 
limited product adaptation, means that issues of customer responsiveness and significant delivery times might be less pressing for our respondents. Finally, perhaps the key implication is that our firms see alternatives to reshoring in the face of declining operating conditions or a need to correct suboptimal prior decisions. Changes in governance forms and structures, as illustrated in Figure 1, may be sufficient to offset adverse changes in local conditions or to correct (locally) suboptimal structures. In effect, these alternatives serve to delay or even offset pressures to reshore. This is clearly an area worthy of further research attention.

\section{Conclusions}

This short paper has outlined the key findings from a pilot study of technology-based firms offshoring to China. Our findings confirm much of what is already known, particularly that offshoring is primarily cost driven and seems to contribute to overall firm competitiveness. However, we also discovered some more subtle aspects of offshoring manufacturing. Firms reported other benefits, often unanticipated. The extent of cost savings was linked to governance choice, in essence, greater control over quality or intellectual property protection comes at the price of reduced savings. Theoretical perspectives on the governance of offshoring do not seem to capture the reality of operating in a relationship-based economy such as China where institutional weaknesses mean that great reliance is placed on networks and relationships. Interestingly, our study reveals some solid data on the extent of cost savings, and these appear to be significant.

These results will help guide the next stage of the research which, using a much larger sample, will examine the choice of governance mode and the triggers that initiate mode switches.
Peter Enderwick (peter.enderwick@aut.ac.nz) is Professor of International Business at Auckland University of Technology, Auckland, New Zealand and in recent years a Visiting Professor at the Centre for International Business, University of Leeds, UK. His interests are in the areas of international strategy, international HRM, services and emerging markets. He is the author of a number of books, book chapters and articles in professional journals. He is a member of the Academy of International Business and a founding member of ANZIBA (Australia and New Zealand International Business Academy).

Taghreed K. A. Hikmet (taghreed@hikmet.co.nz) has several years experience working in New Zealand business organisations, and is a postgraduate student at Auckland University of Technology, New Zealand. She completed the masters in business programme with a thesis, "Maintaining competitiveness: the case of New Zealand smallmedium technology manufacturers".

\title{
For more information about the journal and its editorial policy, please visit
}

\author{
https://aib.msu.edu/publications/insights
}

AIB Insights (ISSN: print: 1938-9590; online: 1938-9604) provides an outlet for short, topical, stimulating, and provocative articles. Past copies of the AlB Insights can be accessed through the AIB website at http://aib.msu.edu/publications/

AIB Insights is jointly published with the AIB Newsletter by the Academy of International Business Secretariat. For more information, please contact G. Tomas M. Hult, Executive Director, or Tunga Kiyak, Managing Director, at:
Academy of International Business
G. Tomas M. Hult, Executive Director
Michigan State University
Eppley Center
645 N Shaw Ln Rm 7
East Lansing, MI 48824 USA

Tel: +1-517-432-1452

Fax: +1-517-432-1009

Email: aib@aib.msu.edu

Copyright (C) 2015 Academy of International Business

\section{AIB Insights Editorial Team}

Romie F. Littrell, Ph.D., Editor AUT Business School

Auckland University of Technology New Zealand

Daniel Rottig, Ph.D., Associate Editor Lutgert College of Business

Florida Gulf Coast University USA

insights@aib.msu.edu

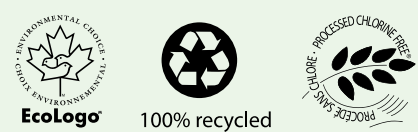

